James R. Harrison

\title{
Paul and the Imperial Authorities at Thessalonica and Rome
}

\author{
A Study in the Conflict of Ideology
}

[Paulus und die imperialen Obrigkeiten in Thessaloniki und Rom. Eine Studie zum Ideologiekonflikt.]

Veröffentlicht auf Englisch.

James R. Harrison untersucht den Zusammenprall zwischen Paulus' eschatologischem Evangelium und dem julio-claudischen

JAMES R. HARRISON

Paul and the

Imperial Authorities at

Thessalonica and Rome

Herrscherkonzept. Die Ideologie des Herrschers mit seinem Anspruch auf die 'Herrschaft auf alle Ewigkeit' des

Herrscherhauses über seine Untertanen verkörpert sich in der Vergötterung der Macht, die im Konflikt mit Paulus'

Verkündigung der Herrschaft des auferstandenen Sohnes Gottes über die Welt stand. Dieser ideologische Konflikt wird anhand der Briefe an die Thessaloniken und Römer untersucht. Dies geschieht im Hinblick auf die Eschatologie des Paulus, die sich in jenen Briefen mit den lokalen Ansprüchen des imperialen Kultes im griechischen Osten und lateinischen Westen kreuzt. Zahlreiche literarische, dokumentarische, numismatische, ikonographische und archäologische Beweisstücke decken das 'symbolische Universum' der julio-claudischen Herrscher auf.

James R. Harrison Born 1952; 1976 BADipEd; 1989 MA; 1997 PhD (Macquarie University); 2002-12 Head of the School of Theology, Wesley Institute, Sydney, Australia; currently Research Director, Sydney College of Divinity, Macquarie Park, Australia.

2011. XV, 428 Seiten. WUNT I 273

ISBN 978-3-16-151562-0

DOI 10.1628/978-3-16-151562-0

eBook PDF 144,00€

ISBN 978-3-16-149880-0

Leinen $144,00 €$

Jetzt bestellen:

https://mohrsiebeck.com/buch/paul-and-the-imperial-authorities-at-thessalonica-and-rome-9783161515620?no_cache=1 order@mohrsiebeck.com

Telefon: +49 (0)7071-923-17

Telefax: +49 (0)7071-51104 